\title{
II - Origem e Atualidade da Administração Internacional
}

Como se pode ver pelo ensalo de Woodrow Wilson - que é uma espécie de fotografia de infância da administração - nasceu ela, por assim dizer, em solo nacional, ou seja, focalizada para os problemas de um país ou nação.

Transplantada para o terreno mais restrito das cidades, sofreu - como aualquer planta que muda de habitat - transformaçöes mais ou menos consideráveis, adquirindo características próprias e convertendo-se na administração municipal, como nos fol dado o ensejo de assinalar, ainda que de relance, no capítulo introdutório desta obra.

Transportada, por outro lado, para o solo internacional, mals amplo e diversificado, experimenta ela, igualmente, alteraçöes bastante profundas e significativas, num de seus mais recentes desenvolvimentos.

Tudo isso é muito natural e compreensível, principalmente após a formulação do enfoque ecológico da administração, pois, como já o observava John Merriman Gaus há um quarto de século, "changes in place, or the use of the resources and products of a place, are coercitive in their effects upon public administration" (5).

E o que Gaus afirma da administração pública, evidentemente, é válido, por Igual, para a administração de negócios e para a administração de modo geral.

Ou, como Lyman A. Keith e Carlo E. Gubellinl colocaram a questão, ercarando-a pelo prisma dos negócios e da perspectiva norte-americana:

"American business cannot operate abroad in the same way as it does at home. Business, no matter where it is conducted, is a creature " of its environment" (6).

Uma nova modalidade ou disciplina administrativa, a administração internacional, com características e peculiaridades próprias, está, pois, em pro-

(5) Reflections on Public Administration, Alabama, Unlversity of Alabama Press, 1948, p. 13.

(6) Introduction to Business Enterprise, New York, McGraw-Hill Book Company, 1971, p. 579 . 
cesso de formação desde o fim da Segunda Guerra Mundial e, em especial, nestes últimos quinze ou vinte anos, conforme vem sendo assinalado por vários autores.

John Fayerweather, por exemplo, em volume consagrado exclusivamente à administração internacional de negócios, escreve :

"Os negócios internacionais, de certo modo, contam com milhares de anos de existência e remontam, além dos fenícios, aos primeiros comerciantes dos tempos primitivos. Mas, no sentido atual de um grande número de empresas com produção interligada e operações de vendas em toda a terra, constituem eles fenômeno recente, que somente apareceu nos anos 50" (7).

Richard N. Farmer, em obra já traduzida para o vernáculo, - depois de afirmar que a administração internacional, como campo específico de investigação e prática, é conceito tão recente que ainda não se chegou a um consenso sobre as suas próprias delimitações ou fronteiras - registra, por sua vez:

"Até a década de 1960, pouca reflexão haviam merecido as questões de administração internacional, mas a crescente maré de atividades multinacionais, postas em prática por firmas americanas, resultou em uma explosão de publicações de materiais dedicados aos negócios e à administração internacionais"' (8).

É o que também afirma, por outras palavras, Franklin R. Root, prefaciador do livro de John Fayerweather:

"Os negócios internacionais constituem jovem e exuberante campo de estudo".

E mais adiante:

"Com o advento da empresa multinacional, o estudo dos negócios internacionais explode em todas as direções" (9).

O mundo de nossos dias está, assim, sob o impacto de uma nova dimensão da administração: a dimensão internacional.

(7) International Business Management : A Conceptual Framework, New York, McGraw-Hill Book Company, 1969, p. 1.

(8) Administração Internacional, São Paulo, EPV - Editora Pedagógica Universitária Ltda., 1973, p. 3. (Foi respeitada a redaçăo do tradutor da obra para o português).

(9) John Fayerweather, Op. cit., p. vii.

R. Serv. públ., Brasília, 109 (4) out./dez. 1974 
A empresa ou organização - tanto pública ou semi-pública, como privada - se internacionaliza; e a administração, que é a ciência ou arte de gerir empresas ou organizações, tem de acompanhá-las, internacionalizando-se também.

A dimensão internacional que a administração foi obrigada a assumir em nossos dias resulta, em verdade, sobretudo de dois novos tipos de organização, que passaram a proliferar na face da terra, principalmente depois da Segunda Guerra Mundial:

a) os organismos internacionais;

b) as empresas multinacionais.

Os primeiros começaram a surgir depois da Primeira Guerra Mundial, com o advento da Sociedade ou Liga das Nações, criada em 1919 pelo Tratado de Versalhes (10).

Foi, todavia, após a Segunda Guerra Mundial, com a criação da Organização das Nações Unidas (ONU), que esses organismos, em verdade, passaram a se multiplicar sobremaneira.

A ONU, por exemplo, o mais conhecido e eminente de todos os orgarismos internacionais, compreende hoje uma familia de dezesseis organizações com quase 50.000 servidores e sedes em vários países, como se pode ver pela discriminação a seguir :

\section{Em Nova lorque :}

- Nações Unidas, propriamente ditas, ou ONU, tout-court, criada a 24 de outubro de 1945.

\section{Em Washington :}

- Banco Internacional de Reconstrução e Desenvolvimento (BIRD), ou Banco Mundial, criado a 27 de dezembro de 1945.

:- Fundo Monetário Internacional (FMI), criado a 27 de dezembro de 1945.

- Corporação Financeira Internacional (CFI), criada em julho de 1956.

(10) Umas poucas organizações internacionais, que hoje fazem parte da família das Nações Unidas, como a União Internacional de Telecomunicações (UIT) e a União Postal Universal (UPU), foram criadas no século passado, a saber, em 1865 e em 1875, respectivamente. Mas, são exceçőes.

R. Serv. públ., Brasília, 109 (4) out./dez. 1974 
- Associação Internacional de Desenvolvimento (AID), criada a 24 de setembro de 1960 (11).

\section{Em Montreal :}

- Organização da Aviação Civil Internacional (OACl), criada a 4 de abril de 1947.

\section{Em Genebra :}

- União Internacional de Telecomunicações (UIT), criada em 1865.

- União Postal Universal (UPU), criada em 1875.

- Organização Internacional do Trabalho (OIT), criada a 11 de abril. de 1919.

— Organização Mundial de Saúde (OMS), criada a 22 de julho de 1946.

- Organização Meteorológica Mundial (OMM), criada a 23 de março de 1950.

- Acordo Geral sobre Tarifas e Comércio (GATT), criado em 1948.

\section{Em Paris :}

- Organização das Nações Unidas para a Educação, a Ciência e a Cultura (UNESCO), criada a 4 de novembro de 1946.

\section{Em Roma :}

- Organização das Nações Unidas para a Agricultura e a Alimentação (FAO), criada a 16 de outubro de 1945 (12).

\section{Em Londres :}

- Organização Consultiva Marítima Intergovernamental (OCMI), criada a 6 de março de 1948 (apesar de que, praticamente, só em 1958 haja entrado em funcionamento efetivo).

(11) Năo confundir, obiviamente, com a USAID (United States Agency for International Development), que é o organismo da administração norte-americana para o desenvolvimento internacional.

(12) As siglas, praticamente universais, do GATT, da FAO e da UNESCO, resultam das suas denominações em inglês: General Agreement on Tariffs and Trade, U.N. Educational, Scientific and Cultural Organization e Food and Agriculture Organization of the U.N.

R. Serv. públ., Brasília, 109 (4) out./dez, 1974 


\section{Em Viena :}

- Agência Internacional de Energia Atômica (AIEA), criada a 29 de julho de 1957 (13).

As empresas multinacionais, por sua vez, surgiram em data mais recente ainda, conforme ficou indicado atrás, ou seja, principalmente nos últimos três ou quatro lustros.

Resultaram, sobretudo, da necessidade que tiveram os paises desenvolvidos de mudarem a sua política comercial e industrial para com boa parte dos países subdesenvolvidos ou em desenvolvimento.

Em verdade, até a Segunda Guerra Mundial, limitavam-se, praticamente, os países desenvolvidos a comerciar, pura e simplesmente, com os países em desenvolvimento, exportando-lhes bens manufaturados que produziam em seu próprio território com administração e pessoal nacionais.

Após a Segunda Guerra Mundial e, em especial, a partir da década de 1950, passaram as grandes indústrias das naçöes desenvolvidas a instalar-se nas nações em desenvolvimento, não só para ampliar os seus mercados $\theta$, inclusive, utilizar equipamentos tornados em parte obsoletos nos países de origem pelos progressos da tecnologia, como também por exigência de muitos Sovernos das nações em desenvolvimento, que aspiravam também a industrializar-se e deixar de serem meros produtores de matérias-primas, que exportavam, nem sempre a preços convenientes, em troca de bens manufaturados.

É o que reconhece, entre muitos outros, Franklin R. Root, ao escrever as seguintes palavras, que deixamos de traduzir para não lhes tirar o sabor tipico :

"Before World War II the characteristic response of American companies to market opportunities abroad was via direct export from homebased plants. Although direct exports remain important, the most dynamic form of international business today is the transfer of management, technology, and capital via direct investment in foreign economies. A new business organization - the multinational corporation - has come to the fore, and it now sets the pace for international business throughout the world" (14).

vez :

E Herbert Hicks não pode, igualmente, deixar de reconhecer, por sua

(13) A. Fonseca Pimentel, A Paz o o Pão (Desafio às Naçôes Unidas), 2." ed., Rio de Janeiro, Fundação Getúlio Vargas, 1971, pp. 14-17. - Para uma visão panorâmica dos principals organismos internacionais do mundo contemporâneo, veja-se o Apêndice B.

(14) John Fayerweather, Op. cit., p. vii (Editor's Foreword). 
"Acham-se em marcha algumas tendências altamente significativas no sentido de se moverem os negócios cada vez mais em operações internacionais. A título de exemplo, mencione-se que cerca de 137 corporações norte-americanas possuem, cada uma, subsidiárias em um número de países que variam entre 10 e 14. Companhias holandesas têm 35 subsidiárias nos Estados Unidos, enquanto empresas norte-americanas contam com 530 subsidiárias na Holanda. Dentro das fronteiras do Japão existem 465 firmas internacionais, das quais 17 têm sede na Alemanha Ocidental, 33 na Inglaterra e 373 nos Estados Unidos.

"Essa internacionalização dos negócios criou uma quantidade de novos desafios para a administração de firmas multinacionais. Especialmente complexa é a avaliação das potencialidades de mercado para a organização nas contingências econômicas, políticas e sociais, não raro pouco conhecidas, de outros países. Há muita possibilidade de que não poucos leitores do presente texto venham a lidar com tais problemas. Em vez de se deslocarem para outro ponto do pais - como foi usual nos últimos cincoenta anos - o formando de hoje tem cada vez mais chance de despender uma boa parte de sua vida trabalhando no exterior" (15).

Em breves palavras, como se expressam Keith e Gubellini, já citados :

"Over the years our involvement business overseas has shifted from foreign trade - buying and selling in foreign markets - to the building and operating of business abroad" (16).

Como resultado disso tudo, conforme o demonstraram, inclusive ao mundo leigo, Jean-Jacques Servan-Schreiber e James McMillan \& Bernard Harris, as multinacionais, principalmente de origem norte-americana, dominam, de modo absoluto, o mundo dos negócios internacionais (17).

Daí a necessidade, como exigência inelutável de nossos dias, de uma administração internacional, apta a lidar adequadamente com os problemas de produção, recursos humanos, orçamento, organização e métodos, material, comunicações, serviços gerais etc., desse complexo de organismos internacionais e empresas multinacionais que caracterizam o mundo de hoje.

(15) The Management of Organizations: A Systems and Human Resources Approach. 2nd ed., New York, McGraw-Hill Book Company, 1972, p. 488.

(16) Lyman A. Keith e Carlo E. Gubellini, Op. cit., p. 579.

(17) Le défi américain, Paris, Editions du Seuil, 1967, do primeiro, e A Invasão Econômica Americana, Rìo de Janeiro, Editora Expressão e Cultura, 1968, dos últimos.

R. Serv. públ., Brasília, 109 (4) out./dez. 1974 